\title{
Influence of Pranayama on Respiratory Function of Middle Age Women
}

\author{
Manoj Kumar Murmu \\ Asst. Professor, Post Graduate Govt. Institute for Physical Education, \\ Banipur, North 24 PGS, West Bengal, India
}

\begin{abstract}
The aim of this study was to determine the occurrence of respiratory function by measuring vital capacity and Breath holding. The investigator adopted experimental method of research on 40 middle aged women ranged from 41-45 years. The experimental groups participated in Pranayama training for a period of twelve weeks. Prior to the study, vital capacity and breath holding of all the subjects were taken. Based upon these values, vital capacity and breath holding was calculated before and after the fitness training. Pranayama begins with breathing guidance and completes full control over the streams of life or within the basics. The effects of pranayama on selected physiological variables, dependent' $t$ ' test was applied at 0.05 level of significance to find out the significance among the mean differences. Participants assigned to Pranayama training revealed a significant improvement in respiratory function $(p<0.05)$.
\end{abstract}

Keywords:- Pranayama, Respiratory Function, Middle Age, Vital Capacity, Breath Holding.

\section{INTRODUCTION}

People today are worried about work deception, work failures, over-load data, focusing points and the growth of living standards. "Yoga on Daily Life" is a comprehensive system, which reflects on environmental considerations, and in addition to points of viewpoint and significance. Ideal thinking, adaptation, preparation, introduction, promotion and thinking and understanding of a building are a better way to deal with exercise and pride. Though yogic exercises develop most of the components of fitness, it is expected that it will have an effect on the body composition, obesity and hypertension. Some modern texts seem to indicate that yogic exercises will strengthen all organs and all physiological functions of the body.

Pranayama the fourth element of the eightfold Path Yoga is the control of 'Vital Force' or 'Cosmic energy' by meditation and systematical breathing. Air control makes life-control control or prana and cerebrum. PRANAYAM reflects breathing and trying to mean control. Pranayama is described as Pana's control and the physical strength of the body. In the form of speech, Pranayama is the complete control of breathtaking streams. Breathe as the power of a great Prana. By placing control over a lot of Prana, you can without diminishing control over Prana's honest inside. Such a control strategy is called Pranayama. Pranayama is the fourth part of Ashtanga Yoga. Prana is very profitable, starting-to-date operation since the second targeted youth. The track looks for food, converts it into circular and blood and sends it into the cerebrum and the brain. Prana is an infinite law of importance or power. Important power Prana is complete.

Regular and systematic practice of Pranayama for long period removes many of the chronic diseases and brings purity of the body. Pranayama is capable of improving the oxygen supply of the blood as no other exercise is, and the practice will act as curatives and preventives of various kinds of mental and physical ailments. The respiratory system must work effectively if the blood supply is to be always kept rich in quality; this supply is adequately enhanced by method for Pranayama. The advantage of practicing Pranayama the body will become light and intellect will turn sharp and clear, enhance the static motor performance, personality development, lung capacity and respiratory, brain functions and physical fitness. During Pranayama in both inspiration and expiration as well as in retention of sound breath relies on solid respiratory muscles and great flexibility of the lungs.

\section{MATERIAL AND METHODS}

The study was formulated as a true random group design, consisting of a pre-test and post-test. Forty women from Raipur, Bankura, West Bengal, India were selected as subjects at random and their ages ranged from 41 to 45 years. The subjects $(\mathrm{N}=40)$ were randomly assigned to two equal groups of twenty subjects each as Experimental Group and Control Group. Pre test and post test was conducted for all the subjects on selected Pulmonary function (PFT). Experimental Group was exposed to Pranayama Practice and Control Group was not exposed to any experimental training other than their regular daily activities. Training stimuli, adopted for a 12 weeks period, was considered here as independent variables. After the experimental treatment, all the forty subjects were tested on their Pulmonary function (PFT). This final test scores formed as post test scores of the subjects.

The vital capacity measures the amount of air one can breathe out with force after one inhales as intensely as possible. In the present study VC were measured by vitalor spirometer (for air shields). Breath holding capacity was to measure the breath holding time. For recording the breath 
holding time, a stop watch (1/10th of second) and nose clip were used.

\section{STATISTICAL ANALYSIS}

The pre test and post test scores were subjected to statistical analysis using dependent' $t$ ' test to find out the significance between the mean differences. The descriptive statistics were used for the calculation of means and standard deviation of the subjects' scores in respiratory function tests. For all analyses, the criterion for significance was set at level of $\mathrm{p}<0.05$.

\section{RESULTS}

Showing $\mathrm{t}$ - Values to find out the Effect of Pranayama on the Respiratory function of Women with respect to the groups

\begin{tabular}{|c|c|c|c|c|c|c|}
\hline \multirow[t]{2}{*}{ Variables } & \multirow[t]{2}{*}{ Groups } & \multicolumn{2}{|c|}{ Pre-test } & \multicolumn{2}{|c|}{ Post-test } & \multirow[t]{2}{*}{$\mathrm{t}$ - value } \\
\hline & & Mean & Std. Deviation & Mean & Std. Deviation & \\
\hline \multirow[t]{2}{*}{ Vital capacity } & Experimental Group & 2.52 & 0.56 & 3.18 & 0.54 & $* 3.3$ \\
\hline & Control Group & 2.55 & 0.48 & 2.59 & 0.45 & 0.29 \\
\hline \multirow{2}{*}{ Breath holding } & Experimental Group & 26.53 & 1.65 & 29.25 & 1.76 & $* 4.95$ \\
\hline & Control Group & 25.40 & 1.72 & 25.5 & 1.75 & 0.18 \\
\hline
\end{tabular}

Table 1

*Significant at 0.05 level

From the above table, we can observe that the significant differences between pretest and posttest for Vital capacity and Breath holding in the experimental group. Since the tvalue of Vital capacity (3.3) and Breath holding (4.95) is more than the table value at 0.05 (2.09) levels of significance. However, there was no significant difference of the control groups at pretest and post test $(\mathrm{P}>0.05)$.

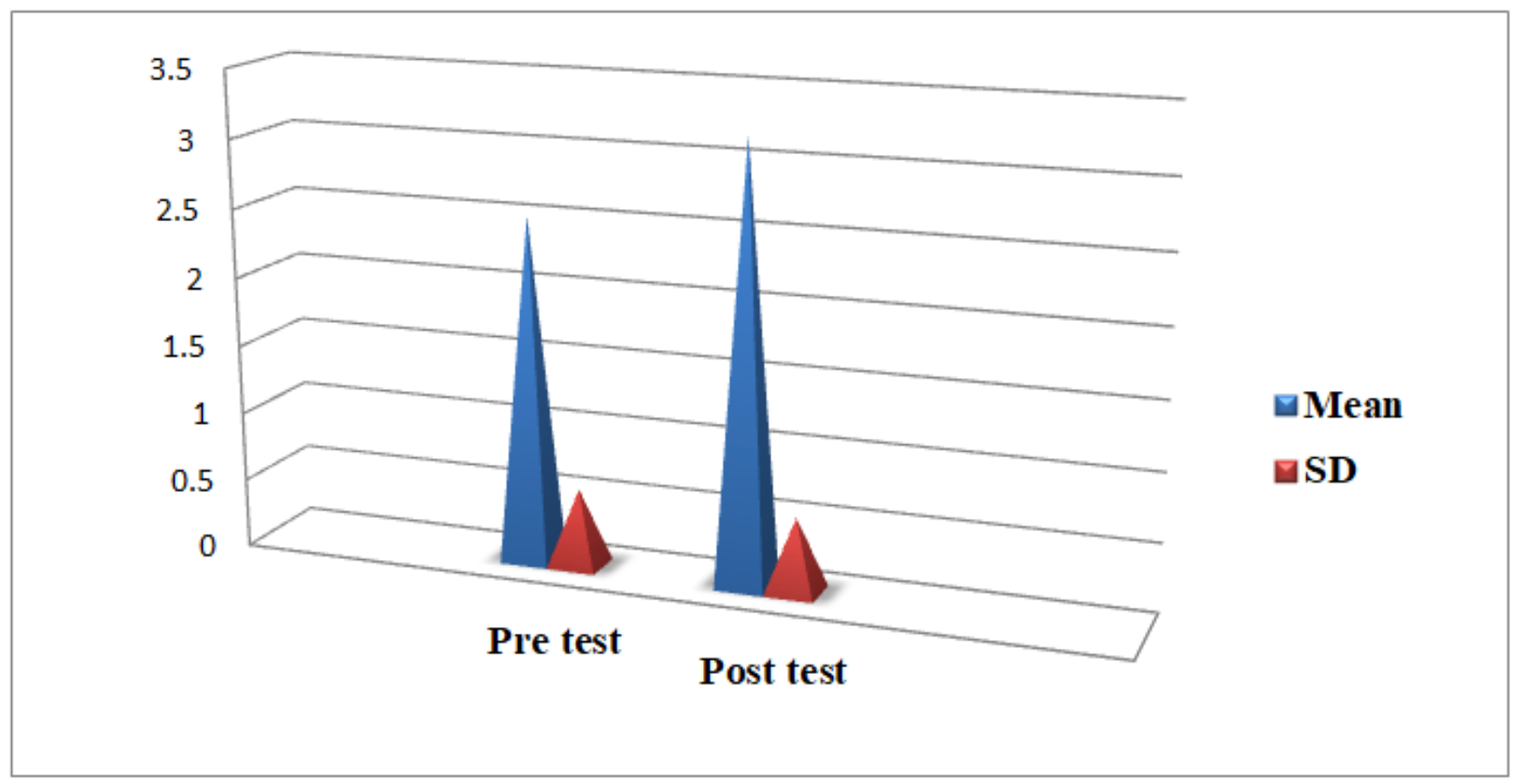

Fig 1:- Bar Graph showing Significance of Mean Difference and Standard Deviation to find out the Effect of Pranayama on the Vital Capacity of Women 


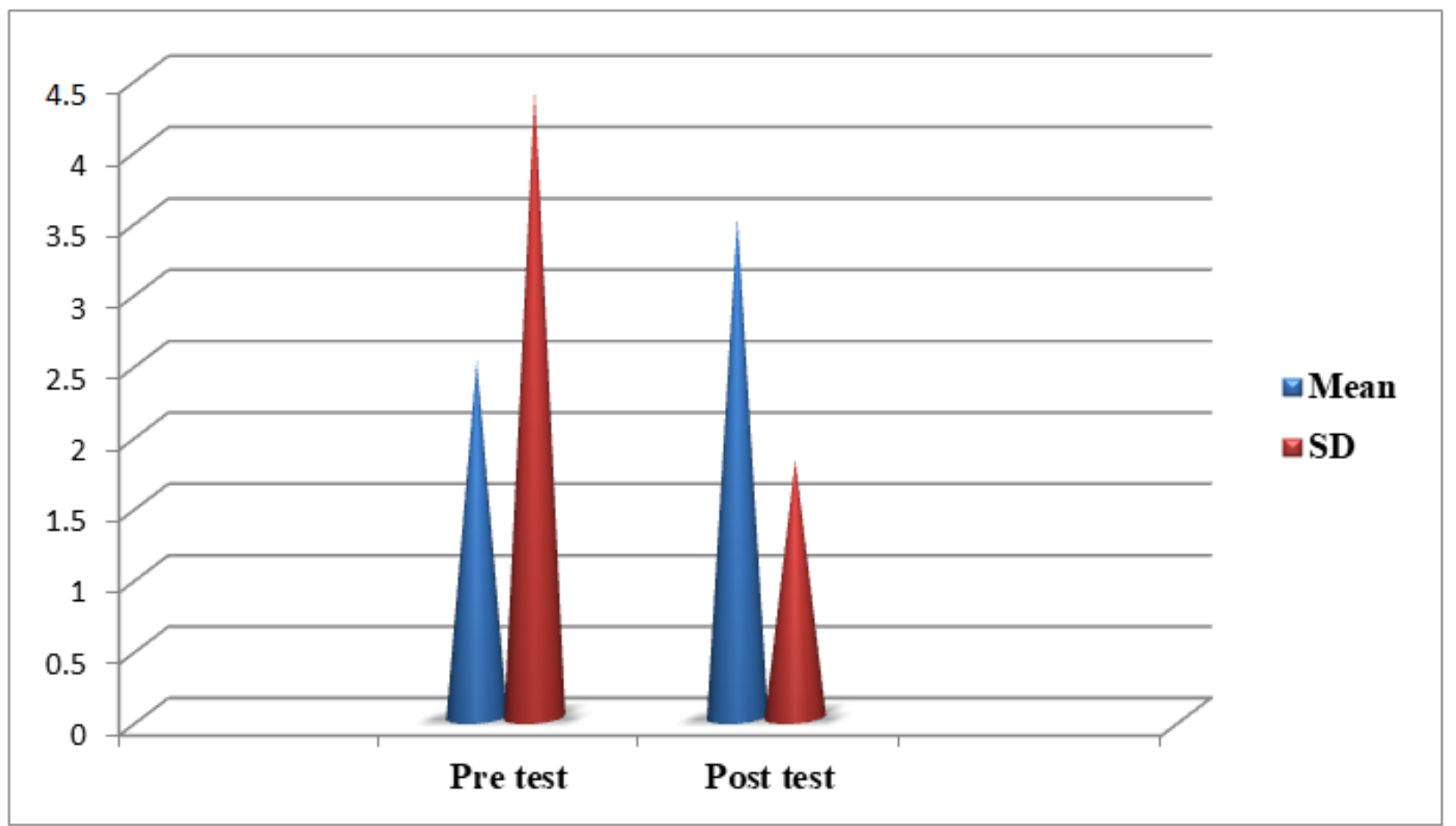

Fig 2:- Bar Graph showing Significance of Mean Difference and Standard Deviation to find out the Effect of Pranayama on the Breath holding capacity of Women

\section{DISCUSSION}

Yoga training programs reduce the risk of pulmonary problems for middle aged women. An inactive life is one of the most of the most important causes of pulmonary problems that is excessive increase in body weight. In many studies have reported that regular practice of pranayama exercises increase respiratory breathing controls can transform the body's ability to feel independent of the cardiovascular the sound of vagin as measured by the value of the heart (Lehrer 1999; Sovik 2000), reasonableness and consideration (Fokkema 1999), the chemoreceptor and the baroreflex installed (Bernardi 2001; Spicuzza 2000), and the persistence of internal problems (Brown and Gerbarg 2005). Prana development (endless life) that strengthens respiratory muscles and better drinks; Mudra (flag) seal type-body development to hold the importance, or consider care; and Bandha is a jolt imperativeness, which uses strong correction to concentrate on care (Raub, 2002). The first experiments (Josh et al., 1992; Miller and al., 1988) show a change in couples, but not all, steps to rest after breathing spirit alone. The study conducted by Savitha \& Anbalagan (2014), Senthil Kumar (2013) proved that there was an improvement in breath holding time.

\section{CONCLUSION}

The present researcher has tried to find out the effect of pranayama practice on physiological component of middle aged women the study have been found to be much significant on the variables selected for the study in contrast to control group. The problem existing today is that life style habits that are likely to become the foundations of their ageing problems can reduce and maintain good muscle tone or cardio-vascular and respiratory fitness. On the physiological variable where the middle aged women have been found to possess higher improvement after the pranayama practice should find favorite to promote pranayama training among the subjects and often prevent, balance, or minimize the effects of aging. Regular practice of pranayama to be a very effective can cure health risk and mitigate the physiological system among the female individuals $(p<0.05)$. Besides, this study ascertained that the pranayama exercise contributes to the developed of Vital capacity, Breath holding and accordingly it may be effective in the improved health, it also prolong the power of his mind and then awakens his realization in middle aged women.

\section{REFERENCES}

[1]. Annakili, C.M. (1993). A Comparative Study of Yoga Asana and Gymnastic In Selected Physical, Physiological and Psychological Variables. Unpublished M.Phil thesis, Alagappa University, India.

[2]. Bal, Baljinder, Singh (2010). Effect of anulom vilom and bhastrika pranayama on the vital capacity and maximal ventilatory volume. Journal of Physical Education and Sport Management Vol. 1(1).

[3]. Bal, Baljinder, Singh, S. Kanwaljeet and K. Parminder (2009). Effects of Kapalbhati on Peak Expiratory Flow Rate and Pulse Rate. International Journal of Sports Science and Engineering Vol. Ill, No. 02.

[4]. Buch. M.B. (Ed). (1991). Sixth Survey of Research in Education (1993-2000), New Delhi: vol. II, NCERT, New Delhi.

[5]. Carman WJ, Sowers M, Hawthorne VM, Weissfeld LA. Obesity as a risk factor for osteoarthritis of the hand and wrist: a prospective study. Am J Epidemiol. 1994; 139:119-29. 
[6]. Earners, Mildred, et. al. 1966. Sports Activities for Girls and Women. Meredith Corporation: New York.

[7]. Furjan-Mandić G, Kosalec V, Vlašić J. The effects of aerobic exercise on the increase of repetitive strength in women. In S. Simović (Ed.), 3th International aspects of Sports, Physical education and Recreation. 2011, 75-83.

[8]. Kuvalayananda, Swami. (1966). Pranayama. Bombay: Bombay Popular Prakashan, 35 C, Tardeo Road.

[9]. Joshi, Dr. K.S. 1996. Yogic Pranayama. Orient Paperback; Delhi, India

[10]. Madanmohan, Rai UC, Balavittal V, Thombre DP, Swami Gitananda. Cardiorespiratory changes during savitri pranayam and shavasan. The Yoga Review $1983 ; 3 ; 25-34$.

[11]. Madanmohan, Thombre DP, Bharathi B, Nambinarayanan TK, Thalur S, Krishnamurthy N, Chandrabose A. Effect of yoga training on reaction time, respiratory endurance and muscle strength Indian J Physiol Pharmacol 1992; 36:229-233.

[12]. Moorthy, A.M. (1988). The effect of selected Yogic Practices on Cardio-Vascular Fitness Level of College Men and Women. Yoga Mimamsa, Vol.XXVII, No 1 $\& 2$.

[13]. Naruka, J.S. ('1983). Effect of Pranayama on Circulatory and Respiratory Variables. Unpublished Ph.D. Thesis, Jiwaji University, Gwalior, India. Gwalior, India.

[14]. Swami Kuvalayananda (2005) Pranayama. Kaivalyadhama S.M.Y.M. Samiti Lonavla.

[15]. Vitthaldas Vaishanav. (2007). Yogic Pranayama and improvement of athletes' performance. Aurangabad: Abhijeet Prakashan. 